\title{
Erratum to: Intraoperative spine ultrasound: application and benefits
}

\author{
Ran Harel $^{1,2} \cdot$ Nachshon Knoller $^{1}$
}

Published online: 31 August 2016

(c) Springer-Verlag Berlin Heidelberg 2016

\section{Erratum to: Eur Spine J (2016) 25:865-869}

DOI 10.1007/s00586-015-4222-5

The original version of this article unfortunately contained a mistake. The first affiliation is incorrect. The correct affiliation is given below:

Spine Surgery Unit, Neurosurgery Department, Sheba Medical Center, Ramat-Gan, Affiliated to Sackler Medical School, Tel-Aviv University, Tel-Aviv, Israel.

The online version of the original article can be found under doi:10.1007/s00586-015-4222-5.

\section{Ran Harel}

harelran@gmail.com; Ran.harel@sheba.health.gov.il

1 Spine Surgery Unit, Neurosurgery Department, Sheba Medical Center, Ramat-Gan, Affiliated to Sackler Medical School, Tel-Aviv University, Tel-Aviv, Israel

2 Talpiot Medical Leadership Program, Sheba Medical Center, Ramat-Gan, Israel 